\title{
Thermal and surface properties of hybrid materials obtained from epoxy-functional urethane and siloxane
}

\author{
Lukasz Byczyński ${ }^{1}$ Michał Dutkiewicz ${ }^{2,3}$. \\ Hieronim Maciejewski ${ }^{3,4}$
}

Received: 2 February 2015/Revised: 7 October 2015/Accepted: 23 October 2015/

Published online: 5 November 2015

(C) The Author(s) 2015. This article is published with open access at Springerlink.com

\begin{abstract}
In this work, a series of high-solids crosslinked hybrid networks based on the epoxy-terminated urethane oligomer and the comb-like structure epoxyfunctional siloxane cured with diethylenetriamine, were obtained. The structure of the obtained poly(urethane-siloxane) thermosets was confirmed by FTIR spectroscopy. The samples were submitted to detailed thermal degradation investigations at non-isothermal conditions in nitrogen and air. The contact angles of the coatings and free surface energy calculated by Owens-Wend as well as van OssGood method, were studied. Some coating properties of the obtained hybrid materials were also investigated. The synthesized poly(urethane-siloxane) networks are hydrophobic materials, with free surface energy of $26-29 \mathrm{~mJ} / \mathrm{m}^{2}$. The thermal stability and hardness of these increases with increasing siloxane content.
\end{abstract}

Keywords Polyurethane - Siloxane - Thermal degradation · Free surface energy · High solids · Crosslinking

Łukasz Byczyński

lbyczynski@prz.edu.pl

1 Faculty of Chemistry, Rzeszow University of Technology, Al. Powstańców Warszawy 6, 35-959 Rzeszów, Poland

2 Centre of Advanced Technologies, Adam Mickiewicz University, Grunwaldzka 6, 60-780 Poznań, Poland

3 Poznań Science and Technology Park, A. Mickiewicz University Foundation, Rubież 46, 61-612 Poznań, Poland

4 Faculty of Chemistry, Adam Mickiewicz University, Umultowska 89b, 61-614 Poznań, Poland 


\section{Introduction}

Polyurethanes (PU) because of their good mechanical properties and particularly high abrasion resistance have been used in manufacturing various products, such as, e.g.: foam materials, elastomeric coatings, and anti-corrosive varnishes, widely applied in construction, furniture and automotive industries [1]. Nevertheless, ongoing advancements in technology, medicine, electronics and economy constitute a growing challenge for these materials, connected for instance with environmental requirements or the necessity to increase thermal resistance [1].

Polysiloxanes consist of alternating atoms of silicon and oxygen, and a typical representative of this group of polymers is polydimethylsiloxane (PDMS). Weak interactions mainly resulting from the activity of dispersion forces between chains of these polymers are the reason why siloxanes are characterized with low glass transition temperature $T_{\mathrm{g}}<-120{ }^{\circ} \mathrm{C}$. These polymers also demonstrate relatively low free surface energy values and high thermal stability even up to $300{ }^{\circ} \mathrm{C}$ [2]. Because of all these properties, polysiloxanes are used for various unique purposes in such areas as: electronics, automotive as well as paint and varnish industries. Furthermore, polysiloxane coatings, which are resistant to water and weather conditions, are useful for purposes connected with antiques restoration, hydrophobization of construction materials and in protecting external walls against graffiti, which in our times is a frequently encountered problem [3]. Additionally, due to their neutral physiological effect, siloxanes are also used in cosmetology and pharmacy [3].

The synthesis of hybrid materials combining the properties of both polymers seems to be justified, which is additionally reflected by the latest research reports [4-12] confirming that polyurethanes modified with siloxanes are characterized with lower glass transition temperature and enhanced thermal stability with simultaneously increased hydrophobicity. Because of this they have been used as protective coatings, selective membranes, medical implants and surface modifiers for various polymers and fibers $[7,8,13]$.

However, nowadays technologies designed for manufacturing any kind of products should also be analyzed in terms of broadly understood ecological aspects, at the stage of synthesis, safe application and final waste management of the specific product. In our study, we employed a new approach to obtaining hybrid poly(urethane-siloxanes) based on reactive epoxy and amino groups. Obtaining of a lower viscosity system by employing epoxy-functional urethane oligomer which at later stages is crosslinked by means of an amine at the presence of functionalized polysiloxane has a beneficial pro-environmental effect involving reduction of volatile organic compounds (VOC) in the final product. While synthesis of polyurethane thermosets from urethane derivatives containing epoxy groups has been reported [14, 15], this approach so far has not been employed in obtaining of hybrid poly(urethane-siloxanes). Additionally, we employed a novel type of functionalized polysiloxane with a comb-like chain structure, which has rarely been used for polyurethane modification [16]. 
The aim of our investigations is to extend our preliminary investigations on developing a way of synthesis of environmentally friendly, high-solids materials based on epoxy-functional urethane, and co-poly(dimethyl)(methyl, 3-glycidoxypropyl)siloxane, which are cured with diethylenetriamine [16]. In this paper, we studied the effect of hybrid materials composition on their surface and thermal properties. However, this time in synthesis of epoxy-functional urethane we employed poly(oxytetramethylene)diol with higher molar mass of $2000 \mathrm{~g} / \mathrm{mol}$.

\section{Experimental}

\section{Materials}

Isophorone diisocyanate (IPDI), glycidol, diethylenetriamine (DETA) and dibutyltin dilaurate (DBTDL) from Aldrich were used without further purification. Poly(oxytetramethylene)diol (PTMO, $M_{\mathrm{n}}=2000$ ) was purchased from Aldrich and dried in a vacuum oven at $105{ }^{\circ} \mathrm{C}$ before use. Toluene from Honeywell was distilled and dried over $4 \AA$ molecular sieves. Co-poly(dimethyl)(methyl, 3-glycidoxypropyl)siloxane (EPS) was synthesized in the hydrosilylation reaction of allyl glycidyl ether with co-poly(dimethyl)(methyl, hydrogen) siloxane according to the procedure comprehensive described in [16]. The formation of the desired product was verified by NMR and FTIR analysis:

${ }^{1} \mathrm{H} \mathrm{NMR}\left(\mathrm{CDCl}_{3}, 298 \mathrm{~K}, 300 \mathrm{MHz}\right)(\mathrm{ppm})=0.05\left(18 \mathrm{H}, \mathrm{Si}\left(\mathrm{CH}_{3}\right)_{3}\right) ; 0.07(300 \mathrm{H}$, $\left.\mathrm{Si}\left(\mathrm{CH}_{3}\right)_{2}\right) ; 0.09\left(75 \mathrm{H}, \mathrm{SiCH}_{3}\right) ; 0.51\left(50 \mathrm{H}, \mathrm{SiCH}_{2}\right) ; 1.63\left(50 \mathrm{H}, \mathrm{CH}_{2}\right) ; 2.60,2.78$ (50H, $\mathrm{CH}_{2}$ (oxi)); 3.14 (25H, CH (oxi)); $3.41\left(50 \mathrm{H}, \mathrm{CH}_{2} \mathrm{O}\right) ; 3.41,3.67\left(50 \mathrm{H}, \mathrm{OCH}_{2}\right)$.

${ }^{13} \mathrm{C} \mathrm{NMR}\left(\mathrm{CDCl}_{3}, 298 \mathrm{~K}, 75.5 \mathrm{MHz}\right)(\mathrm{ppm})=-0.56\left(\mathrm{SiCH}_{3}\right) ; 1.06\left(\mathrm{Si}\left(\mathrm{CH}_{3}\right)_{2}\right)$; $1.79\left(\mathrm{Si}\left(\mathrm{CH}_{3}\right)_{3}\right) ; 13.38\left(\mathrm{SiCH}_{2}\right) ; 23.17\left(\mathrm{CH}_{2}\right) ; 44.32\left(\mathrm{CH}_{2}(\mathrm{oxi})\right) ; 50.85(\mathrm{CH}$ (oxi)); $71.40\left(\mathrm{OCH}_{2}\right) ; 74.16\left(\mathrm{CH}_{2} \mathrm{O}\right)$.

FTIR $\left(\mathrm{cm}^{-1}\right)$ : 2961 and $2873\left(v_{\text {sym }}\right.$ and $v_{\text {asym }}$ of $\left.\mathrm{C}-\mathrm{H}\right) ; 1081$ and $1009\left(v_{\mathrm{C}-\mathrm{O}-\mathrm{C}}\right.$ and $\left.v_{\mathrm{Si}-\mathrm{O}-\mathrm{Si}}\right) ; 1258$ and $792 \mathrm{~cm}^{-1}\left(\delta_{\mathrm{C}-\mathrm{H}}\right.$ in $\left.\mathrm{SiCH}_{3}\right) ; 910 \mathrm{~cm}^{-1}$ (oxirane ring).

The structure of synthesized EPS is presented in Scheme 1.

Scheme 1 Structure of copoly(dimethyl)(methyl, 3-glycidoxypropyl)siloxane (EPS)

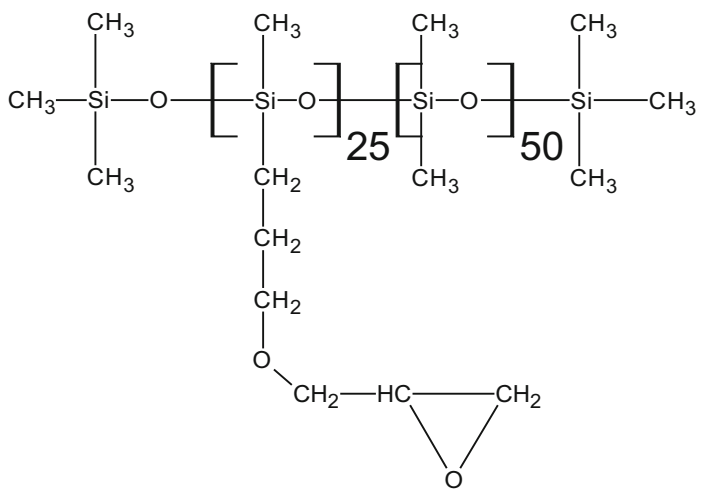


Synthesis of epoxy-terminated polyurethane prepolymer (EPU2)

The epoxy-terminated polyurethane (EPU2) was obtained in a two-step solvent synthesis (Scheme 2). At the first stage IPDI was placed in a 100-ml three-necked flask equipped with a heating mantle, mechanical stirrer, thermometer, reflux condenser and nitrogen inlet and dissolved in toluene. Then PTMO $\left(M_{\mathrm{n}}=2000\right)$ was added drop by drop to the flask. After that DBTDL $(0.02 \mathrm{wt} \%$ with reference to PTMO) as catalyst was added. The reaction was allowed to proceed at $65{ }^{\circ} \mathrm{C}$ till the content of unreacted isocyanate groups reached half of initial value. Then temperature was lowered to $30{ }^{\circ} \mathrm{C}$ and at the second step glycidol was dropwise added. The temperature was increased slowly during the synthesis to about $65^{\circ} \mathrm{C}$ to complete the termination reaction between $-\mathrm{NCO}$ groups from prepolymer and $-\mathrm{OH}$ groups from glycidol. The reaction was monitored by FTIR spectroscopy and samples were taken from the reaction flask every $1 \mathrm{~h}$. The process was continued until NCO peak at $2270 \mathrm{~cm}^{-1}$ disappeared totally at the FTIR spectra. The molar ratio of IPDI : PTMO : glycidol was 2:1:2. The solvent was removed with the use of a rotary evaporator and the obtained product was characterized by ${ }^{1} \mathrm{H},{ }^{13} \mathrm{C}$ NMR and FTIR spectroscopy.

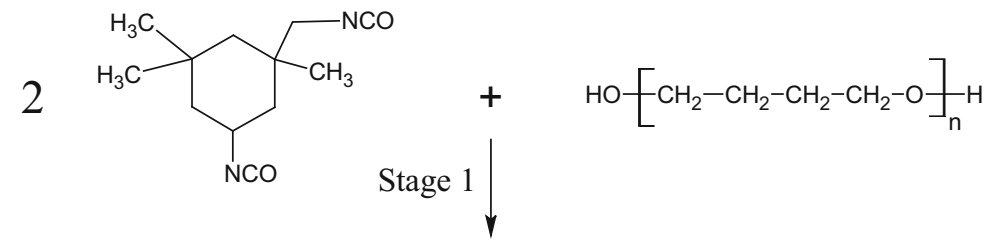

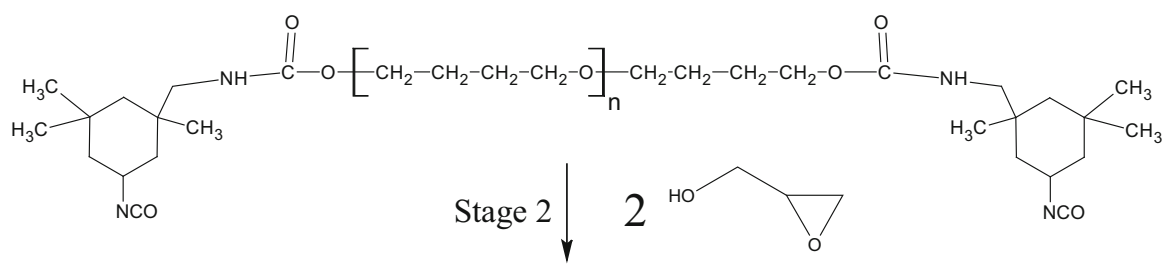<smiles>CC1(CNC(=O)OCCCCCOC(=O)NCC2CO2)CC(NC(=O)OCC2CO2)CC(C)(C)C(C)(CNC(=O)OCCCCCOCC2CO2)C1</smiles>

Scheme 2 Synthesis of epoxy-terminated polyurethane prepolymer (EPU2) 
Table 1 Chemical composition of poly(urethane-siloxane) hybrid materials

\begin{tabular}{lclll}
\hline Sample & $\begin{array}{l}\text { Wt\% of EPS with reference } \\
\text { to EPS + EPU }\end{array}$ & $\begin{array}{l}\text { Wt\% of EPS in } \\
\text { the sample }\end{array}$ & $\begin{array}{l}\text { Wt\% of EPU in } \\
\text { the sample }\end{array}$ & $\begin{array}{l}\text { Wt\% of DETA in } \\
\text { the sample }\end{array}$ \\
\hline PSi0 & 0 & 0 & 98.4 & 1.6 \\
PSi25 & 25 & 24.3 & 73.0 & 2.7 \\
PSi50 & 50 & 48.1 & 48.1 & 3.8 \\
PSi75 & 75 & 71.4 & 23.8 & 4.9 \\
PSi100 & 100 & 94.1 & 0 & 5.9 \\
\hline
\end{tabular}

General procedure of preparation of poly(urethane-siloxane) hybrid materials (PSi)

Required amount of co-poly(dimethyl)(methyl, 3-glycidoxypropyl)siloxane (EPS) and/or the epoxy-terminated polyurethane (EPU2) as well as the appropriate amount of diethylenetriamine (1:1 molar ratio of epoxy: $\mathrm{NH}$ groups) were placed in a beaker according to formulation presented in Table 1 . The beaker content was stirred and placed into an ultrasonic bath in order to remove air bubbles from bulk mixture. Then the composition was poured slowly onto a clean polytetrafluoroethylene or glass plates and cured at $110{ }^{\circ} \mathrm{C}$ for $8 \mathrm{~h}$ and postcured at $135^{\circ} \mathrm{C}$ for $2 \mathrm{~h}$. Using above described procedure 3 samples of crosslinked poly(urethane-siloxane) hybrid materials with varying amount of siloxane $(25,50,75 \mathrm{wt} \%)$ were obtained. Those copolymers are hybrids materials of type II, because they contain chemical bonds between organic (urethane) and inorganic (siloxane) moieties. Additionally, two reference samples of crosslinked EPU and EPS were prepared.

\section{Characterization techniques}

${ }^{1} \mathrm{H}$ and ${ }^{13} \mathrm{C}$ NMR spectra were recorded with the use of the spectrometer FT NMR Bruker Avance $500^{\mathrm{II}}$. The samples were dissolved in $\mathrm{CDCl}_{3}$ and the solution with the concentration of about $0.2 \mathrm{~g} \mathrm{dm}^{-3}$ was prepared. TMS was used as a standard.

FTIR spectra were recorded on a Nicolet iS10 (Thermo Scientific) Fourier transform spectrophotometer equipped with a diamond ATR unit. In all cases 16 scans at a resolution of $4 \mathrm{~cm}^{-1}$ were collected, to record the spectra in a range of $4000-650 \mathrm{~cm}^{-1}$.

Thermogravimetric analyses were performed using a Mettler Toledo TGA/DSC1 apparatus. The TGA experiments have been carried out in nitrogen from 25 to $700{ }^{\circ} \mathrm{C}$ and in air from 25 to $800{ }^{\circ} \mathrm{C}$ at heating rate of $10{ }^{\circ} \mathrm{C} \mathrm{min}{ }^{-1}$. The measurement conditions were as follows: sample weight $\sim 4 \mathrm{mg}$, gas flow

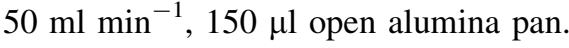

The Persoz hardness of the hybrid coatings on glass plates was measured according to PN-EN ISO 1522:2001 standard in pendulum hardness tester (BYKGardner GmbH, Germany). The Persoz hardness was obtained as the time of 
oscillations decay of the pendulum on material surface to glass constant (407 s). The values obtained were the average of five replicates.

The gloss values of the coatings were measured according to PN-EN ISO 2813:2001 standard with the use of micro-TRI-gloss tester (BYK-Gardner GmbH, Germany) at $20^{\circ}, 60^{\circ}$ and $85^{\circ}$. The values obtained were the average of five measurements.

The contact angles (CA) were measured by the means of an optical goniometer OCA15 EC (Data Physics) with a digital camera installed in axial extension of its lens. The standard liquid drops of water, formamide or diiodomethane with the constant volume of $1 \mu \mathrm{l}$ were employed on the surfaces of studied samples with the use of Hamilton microsyringe. The measurements were taken in temp. at $20 \pm 2{ }^{\circ} \mathrm{C}$ after $10 \mathrm{~s}$ from time of placing the liquid drop. The values of contact angles were found from the geometric analysis of pictures taken for liquid drops. The result of water contact angle was average of 5 measurements.

Method for determination of the free surface energy (FSE) components for solids

Physical parameters of the free surface energy for solids $\gamma_{s}$ were found in the present study on the basis of the van Oss-Good (vOG) [17] and Owens-Wendt (OW) [18] models.

The van Oss-Good's model (Eq. 1) assumes that the free surface energy $\gamma_{S}$ can be presented as a sum of two components [17]:

$$
\gamma_{S}=\gamma_{S}^{\mathrm{LW}}+\gamma_{S}^{\mathrm{AB}}
$$

where $\gamma_{S}^{\mathrm{LW}}$ is free surface energy connected with long-range interactions (dispersion, polar and induction interactions), $\gamma_{S}^{\mathrm{AB}}$, the free surface energy connected with acid-base interactions as results from the Lewis theory which is composed of $\gamma_{S}^{+}$, component related to Lewis acid and $\gamma_{\bar{S}}$, component related to Lewis base.

Taking into account the FSE components in the meaning as it was described above van Oss and Good proposed an equation (Eq. 2) that establishes the relation between the FSE parameters of the standard liquids $(L)$ and of the investigated surface of solid $(S)$ :

$$
\left(\gamma_{S}^{\mathrm{LW}} \gamma_{L, i}^{\mathrm{LW}}\right)^{0,5}+\left(\gamma_{S}^{+}+\gamma_{L, i}^{-}\right)^{0,5}+\left(\gamma_{S}^{-}+\gamma_{L, i}^{+}\right)^{0,5}=\gamma_{L, i} \frac{\left(1+\cos \Theta_{i}\right)}{2}
$$

where $\Theta$ is the experimentally found contact angle between a liquid drop and a solid surface under investigation; $i$, the concerns the used standard liquid.

The Owens-Wendt model (Eq. 3) assumes that the free surface energy $\gamma_{\text {s }}$ of the solid state may be presented as a sum of two components [18]:

$$
\gamma_{S}=\gamma_{S}^{\mathrm{d}}+\gamma_{S}^{\mathrm{p}}
$$

where $\gamma_{S}^{\mathrm{d}}$ is free surface energy connected with dispersion interactions and $\gamma_{S}^{\mathrm{p}}$, the free surface energy connected with polar interactions (polar, hydrogen, induction, and acid-base). 
Using the above described FSE components Owens and Wendt proposed an equation (Eq. 4) that establishes the relation between the free surface energy parameters of the standard liquids $(L)$ and of the investigated surface of solid $(S)$ :

$$
\gamma_{L} \frac{1+\cos \Theta}{2}=\left(\gamma_{S}^{\mathrm{d}} \gamma_{L}^{\mathrm{d}}\right)^{0,5}+\left(\gamma_{S}^{\mathrm{p}} \gamma_{L}^{\mathrm{p}}\right)^{0,5}
$$

where $\Theta$ is the experimentally found contact angle between a liquid drop and a solid surface under investigation.

In order to find as well as to validate the values of SFE $\left(\gamma_{S}\right)$ those two method were applied. Moreover, in OW method two sets of standard liquids (waterformamide and diiodomethane-formamide) for the PUS surface investigation were used.

\section{Results and discussion}

\section{Structural analysis of epoxy-terminated polyurethane prepolymer (EPU2)}

The chemical structure of the epoxy-terminated polyurethane prepolymer was verified on the basis of both FTIR as well as ${ }^{1} \mathrm{H}$ and ${ }^{13} \mathrm{C}$ NMR spectra.

Figure 1 shows the IR spectra of the EPU2 sample. An absence of -NCO peak at $2270 \mathrm{~cm}^{-1}$ indicates, that the isocyanate conversion was complete. The characteristic absorption peaks of polyurethane can be found at around $3327 \mathrm{~cm}^{-1}(-\mathrm{NH}$ stretching), $1720 \mathrm{~cm}^{-1} \quad(-\mathrm{C}=\mathrm{O}$ stretching, first amide band $), 1531 \mathrm{~cm}^{-1}(-\mathrm{NH}$

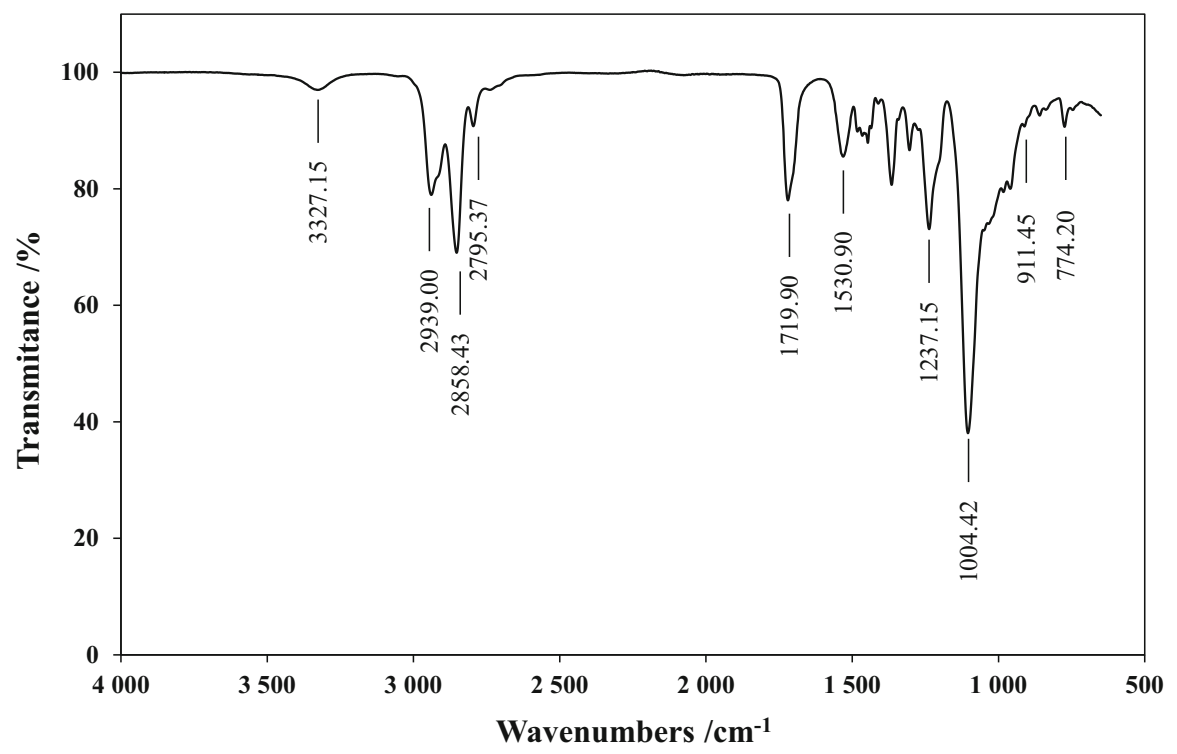

Fig. 1 FTIR spectrum of epoxy-terminated polyurethane prepolymer (EPU2) 
deformation, second amide band) as well as at $1237 \mathrm{~cm}^{-1}$ and at $774 \mathrm{~cm}^{-1}(\mathrm{C}-\mathrm{N}$ stretching, third and fourth amide band). The in-build of oxirane ring was confirmed by the presence of $\mathrm{C}-\mathrm{O}$ stretching at $911 \mathrm{~cm}^{-1}$. Other characteristic IR bands can be found at around $1104 \mathrm{~cm}^{-1}(-\mathrm{C}-\mathrm{O}-\mathrm{C}-$ bending $)$ and in the range of 2750-3000 $\mathrm{cm}^{-1}$ (C-H stretching).

${ }^{1} \mathrm{H}$ and ${ }^{13} \mathrm{C}$ NMR spectra of EPU2 are presented in Figs. 2 and 3, where the signals of protons and carbons were assigned to the particular structural parts of the polyurethane chain. The recorded NMR spectra fully confirmed the structure of epoxy-terminated polyurethane prepolymer.

The formation of urethane was confirmed by the presence of chemical shift at ca. 156.46 and $155.94 \mathrm{ppm}$ in ${ }^{13} \mathrm{C}$ NMR spectrum, which are attributed to carbons No. 17 and 18 (-NHCOO-) in urethane bond. The absence of peaks at $124 \mathrm{ppm}$ characteristic for the $\mathrm{C}$ atom in an isocyanate group confirms that IPDI diisocyanate was completely reacted. The same conclusion results from the IR analysis, as well. In ${ }^{1} \mathrm{H}$ NMR spectrum the signals from IPDI rings $(\mathrm{H} 1-\mathrm{H} 5)$ are present in the 0.94-1.75 ppm range. Chemical shifts originating from PTMO 2000 occur at 1.50-1.75 ppm assigned to protons (6) in $-\mathrm{CH}_{2}-$, at 3.41 related with the protons (12) in $-\mathrm{CH}_{2}-\mathrm{O}-$, as well as at $4.05 \mathrm{ppm}$ assigned to protons (15) in $-\mathrm{CH}_{2}-$ OCONH- groups. The chemical shifts of carbons in the above-mentioned groups are also reflected in ${ }^{13} \mathrm{C}$ NMR spectra. Especially, the signals at $\delta=26.50,64.50$ and $70.60 \mathrm{ppm}$ assigned to carbons (6) in $-\mathrm{CH}_{2}-$ (12) in $-\mathrm{CH}_{2}-\mathrm{O}-$, and (15) in $-\mathrm{CH}_{2}-\mathrm{OCONH}-$ groups, respectively. The build-in of glycidol into the structure of urethane prepolymer is confirmed by the presence of the signals at $\delta \approx 2.65,2.84$ and $3.21 \mathrm{ppm}$ assigned to the protons in oxirane ring. The complementary signals of the carbons in ${ }^{13} \mathrm{C}$ NMR spectra are present at 44.58 and 54.95 ppm, respectively.

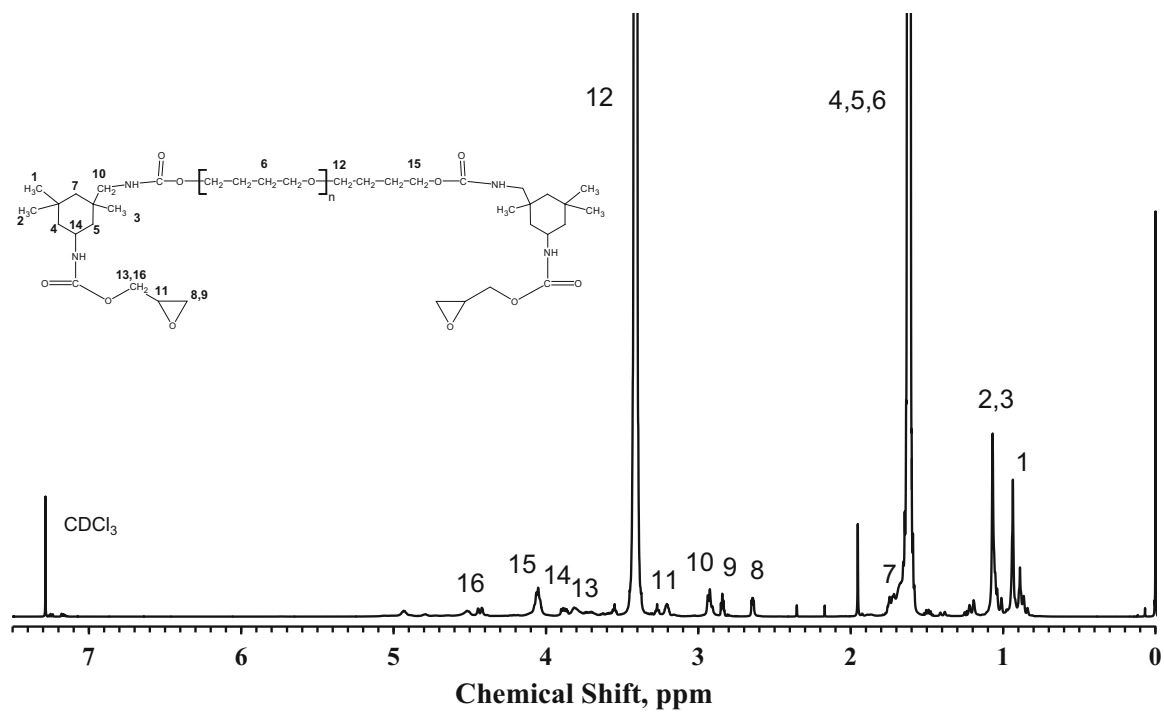

Fig. $2{ }^{1} \mathrm{H}$ NMR spectrum of epoxy-terminated polyurethane prepolymer (EPU2) 


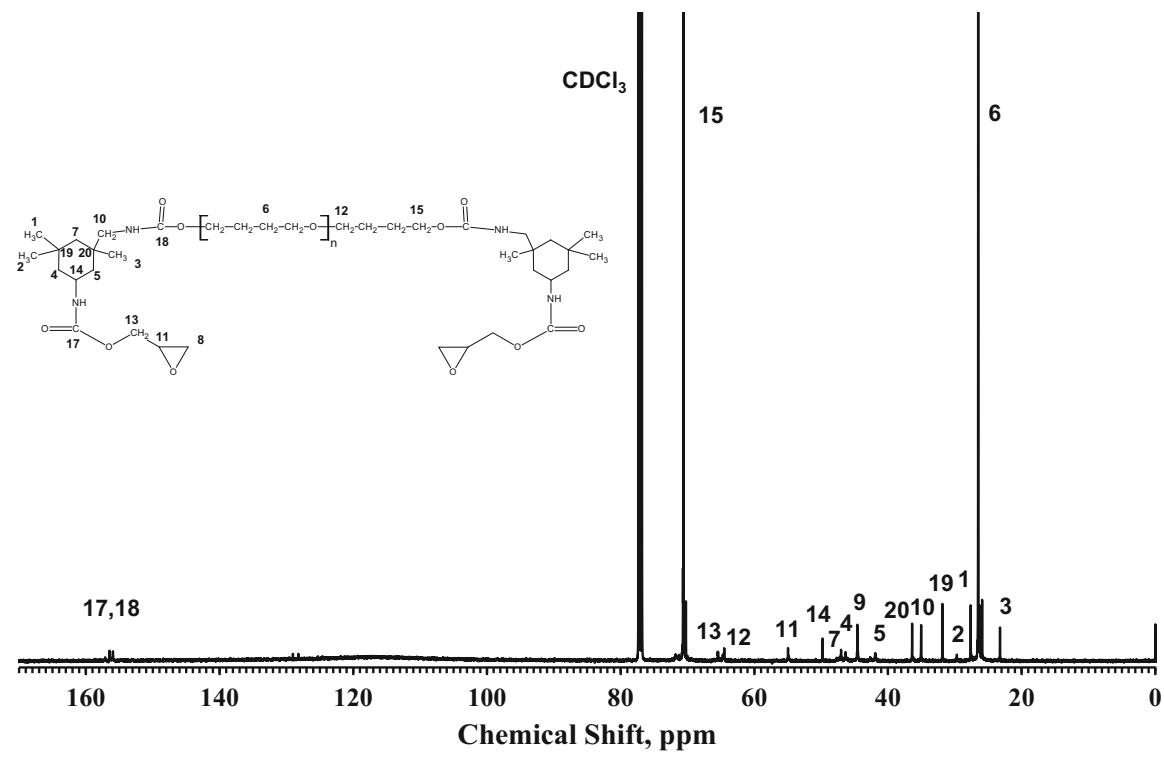

Fig. $3{ }^{13} \mathrm{C}$ NMR spectrum of epoxy-terminated polyurethane prepolymer (EPU2)

\section{Structural analysis of poly(urethane-siloxane) hybrid materials (PSi)}

The chemical structures of the poly(urethane-siloxane) hybrids were verified on the basis of FTIR spectroscopy. Figure 4 shows the IR spectra of all the PSi thermosets. The characteristic absorption peaks of polyurethane can be found $1715 \mathrm{~cm}^{-1}$ ( $-\mathrm{C}=\mathrm{O}$ stretching, first amide band), $1530 \mathrm{~cm}^{-1}$ ( $-\mathrm{NH}$ deformation, second amide band). The intensity of those bands decrease with increasing content of siloxane and in PSi100 sample are no longer present. The build-in of the siloxane segments into the material was confirmed by the presence of the strong $\mathrm{Si}-\mathrm{CH}_{3}$ band at $790 \mathrm{~cm}^{-1}$ and $\mathrm{Si}-\mathrm{CH}_{3}$ deformation band at $1258 \mathrm{~cm}^{-1}$. Similarly the intensity of those bands decrease with increasing EPU2 content. The third $\left(1239 \mathrm{~cm}^{-1}\right)$ and fourth $\left(775 \mathrm{~cm}^{-1}\right.$ ) amide band can be clearly seen only for PSi0, because in the PSi samples those bands are overlapped by the stronger aforementioned bands originating from $\mathrm{Si}-\mathrm{CH}_{3}$ vibrations. In the range of $3100-3600 \mathrm{~cm}^{-1}$ there is a broad band resulting from $-\mathrm{NH}$ and $-\mathrm{OH}$ stretching. The maximum of this band is shifted to larger values with increasing siloxane content, which is related to the formation of more hydroxyl groups. The $-\mathrm{NH}$ vibration derives from urethane segments and while $-\mathrm{OH}$ results from opening of oxirane ring during crosslinking with diethylenetriamine. The absence of the peak at $910 \mathrm{~cm}^{-1}$ indicates, that the epoxy ring conversion was complete. The other characteristic FTIR bands present both in EPU, as well as EPS can be found at around 1010 and $1100 \mathrm{~cm}^{-1}$ (-Si-O$\mathrm{Si}-$ and/or $-\mathrm{C}-\mathrm{O}-\mathrm{C}-$ bending) and $2790-3000 \mathrm{~cm}^{-1}$ (C-H stretching). The absorbance of band at ca. $1010 \mathrm{~cm}^{-1}$ increases, whereas that at ca. $1100 \mathrm{~cm}^{-1}$ 


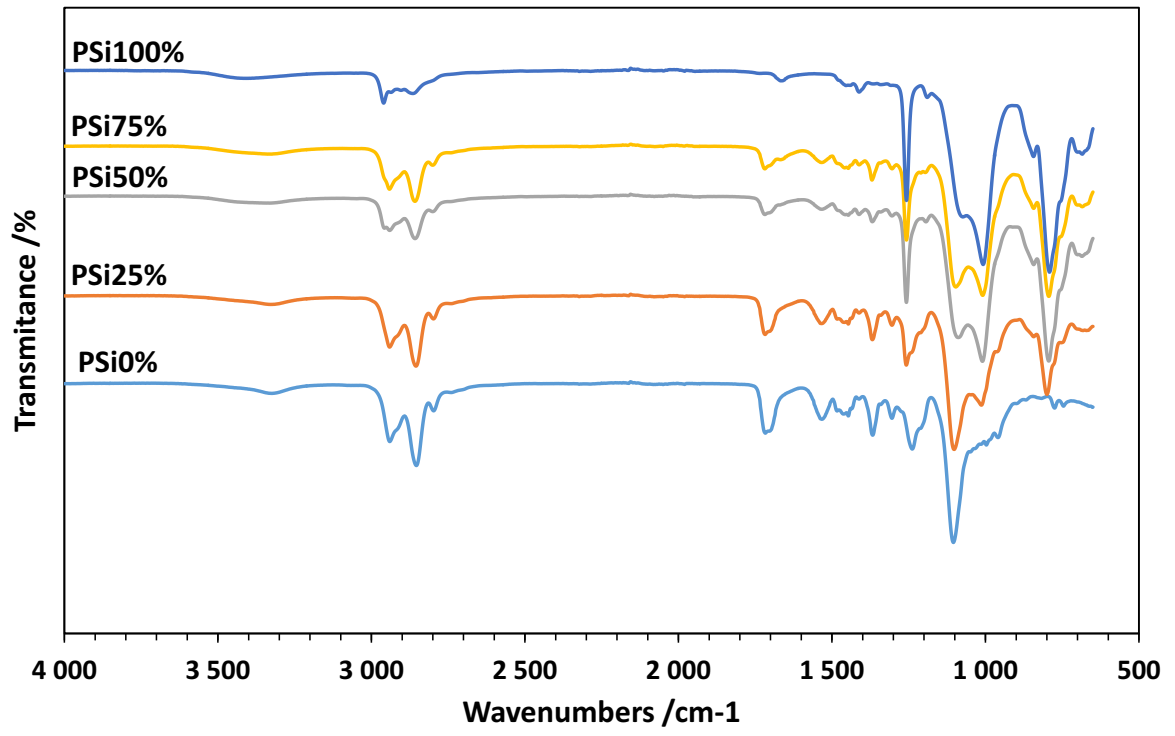

Fig. 4 FTIR spectra of poly(urethane-siloxane) hybrid materials (PSi)

decreases with the increase of siloxane, which can indicate that they are associated with vibrations in $-\mathrm{Si}-\mathrm{O}-\mathrm{Si}-$ and $-\mathrm{C}-\mathrm{O}-\mathrm{C}-$, respectively.

\section{Thermal properties of PU-PDMS copolymers}

\section{Thermal degradation in nitrogen}

The samples of crosslinked poly(urethane-siloxane) were investigated by thermogravimetric analysis to determine their thermal stability. TG and DTG curves recorded at $10{ }^{\circ} \mathrm{C} \min ^{-1}$ heating rate in nitrogen are presented in Fig. 5, whereas Table 2 provides their interpretation.

On the basis of thermogravimetric analyses one may conclude, that crosslinked urethane oligomer (PSi0) decomposes at least in two main stages in the range of $205-500{ }^{\circ} \mathrm{C}$. The first stage of degradation occurs at $205-370{ }^{\circ} \mathrm{C}$ accompanied by $19 \%$ mass loss is related to the scission of the weakest linkage in molecule, which is undoubtedly urethane bond. The second stage of decomposition is related with the degradation of soft PTMO 2000 segments. The mass loss at this stage amounts to $\Delta m_{2}=80.3 \%$. The temperature of the maximum rate of weight loss at first $\left(T_{\max 1}\right)$ and second $\left(T_{\max 2}\right)$ stage amounts to 316 and $413{ }^{\circ} \mathrm{C}$, respectively. However, the crosslinked siloxane sample (PSi100) reveals one-stage degradation mechanism in the temperature range of $300-600{ }^{\circ} \mathrm{C}$. The temperature of the maximum rate of weight loss, which is accompanied by total mass loss of 88.5 amounts to $401{ }^{\circ} \mathrm{C}$.

Similarly to the PSi0, all the crosslinked poly(urethane-siloxane) samples decompose at least in two main stages in the range of $205-580{ }^{\circ} \mathrm{C}$. The first stage of degradation for the PSi25\% sample accompanied by $16 \%$ mass loss occurs at 
(a)
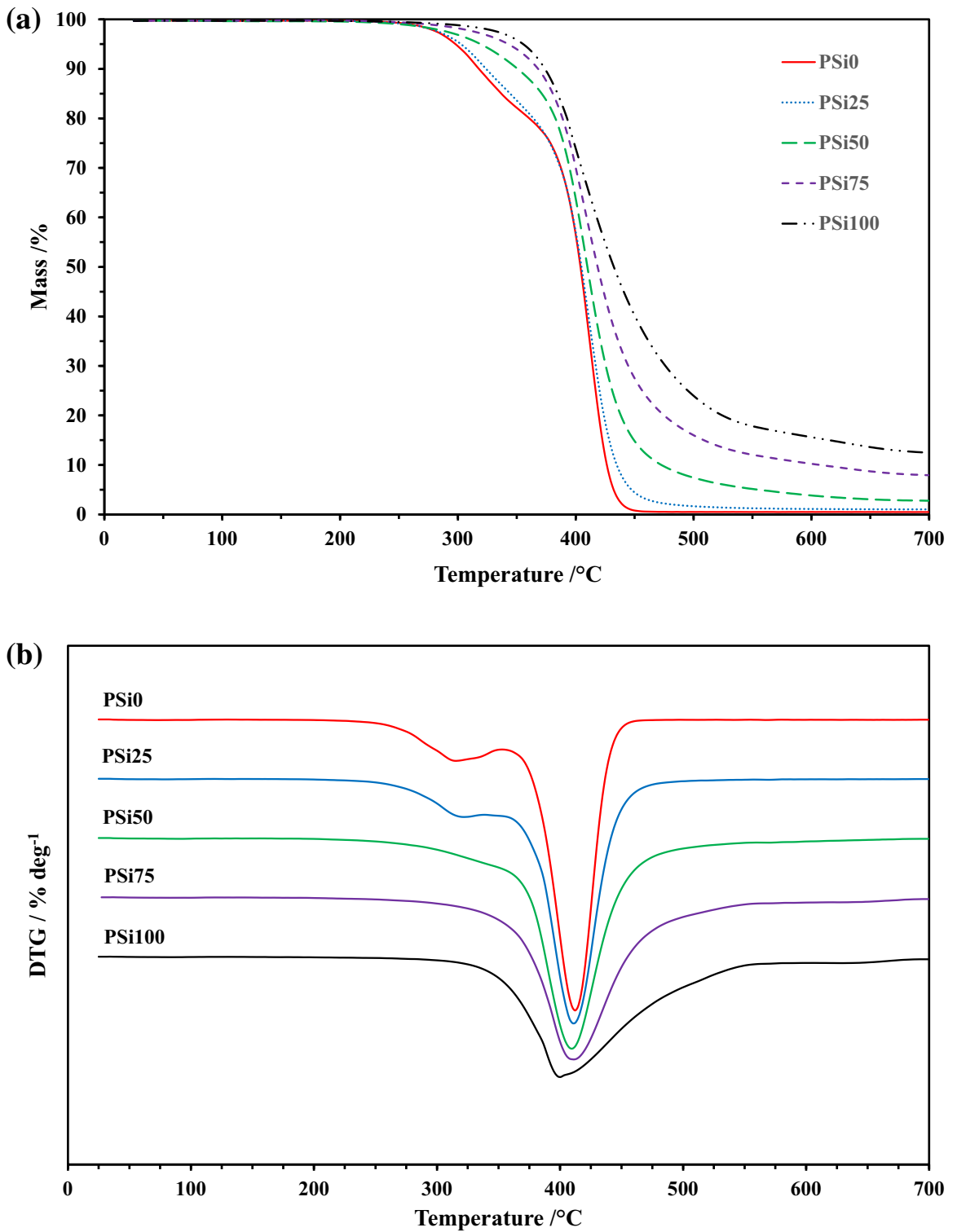

Fig. 5 TG (a) and DTG (b) curves of poly(urethane-siloxane) hybrid materials in nitrogen

205-350 ${ }^{\circ} \mathrm{C}$ and is related to the scission of urethane bond. However, a detailed analysis of DTG curves revealed the presence of shoulder peak in temperature range of $300-350{ }^{\circ} \mathrm{C}$ for the samples with $50 \mathrm{wt} \%$ of siloxane, whereas for PSi75 \% the first step of degradation is not observable in temperature range of $205-370{ }^{\circ} \mathrm{C}$. This may suggest a more complex mechanism of thermolysis at first decomposition stage, involving degradation of siloxane moieties, as well [19]. The mass loss at this 
Table 2 Interpretation of TG and DTG curves of poly(urethane-siloxane) samples recorded at $10{ }^{\circ} \mathrm{C}$ $\min ^{-1}$ in nitrogen

\begin{tabular}{lllllll}
\hline Sample & $T_{5} \%\left({ }^{\circ} \mathrm{C}\right)$ & $T_{\max 1}\left({ }^{\circ} \mathrm{C}\right)$ & $\Delta m_{1}(\%)$ & $T_{\max 2}\left({ }^{\circ} \mathrm{C}\right)$ & $\Delta m_{2}(\%)$ & Remaining mass $(\%)$ \\
\hline PSi0 & 298 & 316 & 19.0 & 413 & 80.3 & 0.7 \\
PSi25 & 303 & 322 & 16.0 & 412 & 82.5 & 1.5 \\
PSi50 & 320 & $330^{\mathrm{a}}$ & $11.0^{\mathrm{a}}$ & 410 & 83.0 & 6.0 \\
PSi75 & 343 & - & - & 409 & 92.0 & 8.0 \\
PSi100 & 356 & - & - & 401 & 88.5 & 12.5 \\
\hline
\end{tabular}

a The value read from plateau on DTG curve

stage decreases from 19.0 to 11.0 with a decrease of urethane segments, which additionally indicates the scission of urethane bonds at this step. The second stage of degradation occurs in the range of $360-580{ }^{\circ} \mathrm{C}$ and is related to the degradation of soft PTMO segments as well as thermo-stable siloxane moieties [19]. The temperature of the maximum rate of weight loss at this stage decreases, whereas the mass loss residue increases from 82.5 (PSi25) to $92 \%$ (PSi75) with the increased siloxane contribution.

The temperature of $5 \%$ weight loss $\left(T_{5} \%\right)$ depends on siloxane content. The lowest $T_{5} \%=298{ }^{\circ} \mathrm{C}$ reveals crosslinked urethane oligomer (PSi0). With the increase of siloxane contribution in the PSi samples the $T_{5} \%$ increases and attains the largest value of $356{ }^{\circ} \mathrm{C}$ for PSi100 sample. This fact confirms the positive impact of siloxane on the thermal stability of the hybrid materials. Moreover, the amount of solid residue after degradation increases with the increase of EPS content. This may indicate that not only volatile decomposition products of cyclic siloxane structures arise during the degradation, but also the formation of complex silicon-based structures occurs.

The PSi samples reveal larger thermal stability comparing to similar materials but obtained from PTMO with $M_{\mathrm{n}}=1000$, which is reflected in lower $T_{5} \%$ for the latter [19]. The difference in temperature of $5 \%$ weight loss for both sample series exceeds $10{ }^{\circ} \mathrm{C}$. This fact may result from lower amount of thermally weak urethane moieties in the poly(urethane-siloxane) samples obtained from EPU2, that is based on PTMO with larger molar mass.

\section{Thermal degradation in air}

Figure 6 presents TG and DTG curves recorded during the thermal decomposition of poly(urethane-siloxane) thermosets in air and Table 3 provides interpretation of both profiles obtained at $10{ }^{\circ} \mathrm{C} \mathrm{min}^{-1}$ heating rate.

On the basis of TG and DTG analyses one may conclude, that crosslinked polyurethane ( $\mathrm{PSi}$ ) sample decomposes in air in three steps. The first stage of the degradation occurs at $180-380{ }^{\circ} \mathrm{C}$ with the temperature of the maximum rate of weight loss $\left(T_{\max 1}\right)$ equals to $372{ }^{\circ} \mathrm{C}$, whereas the second step-in the temperature range of $380-400{ }^{\circ} \mathrm{C}$ with $T_{\max 2}=397{ }^{\circ} \mathrm{C}$. The third stage of PSi0 degradation is 
(a)
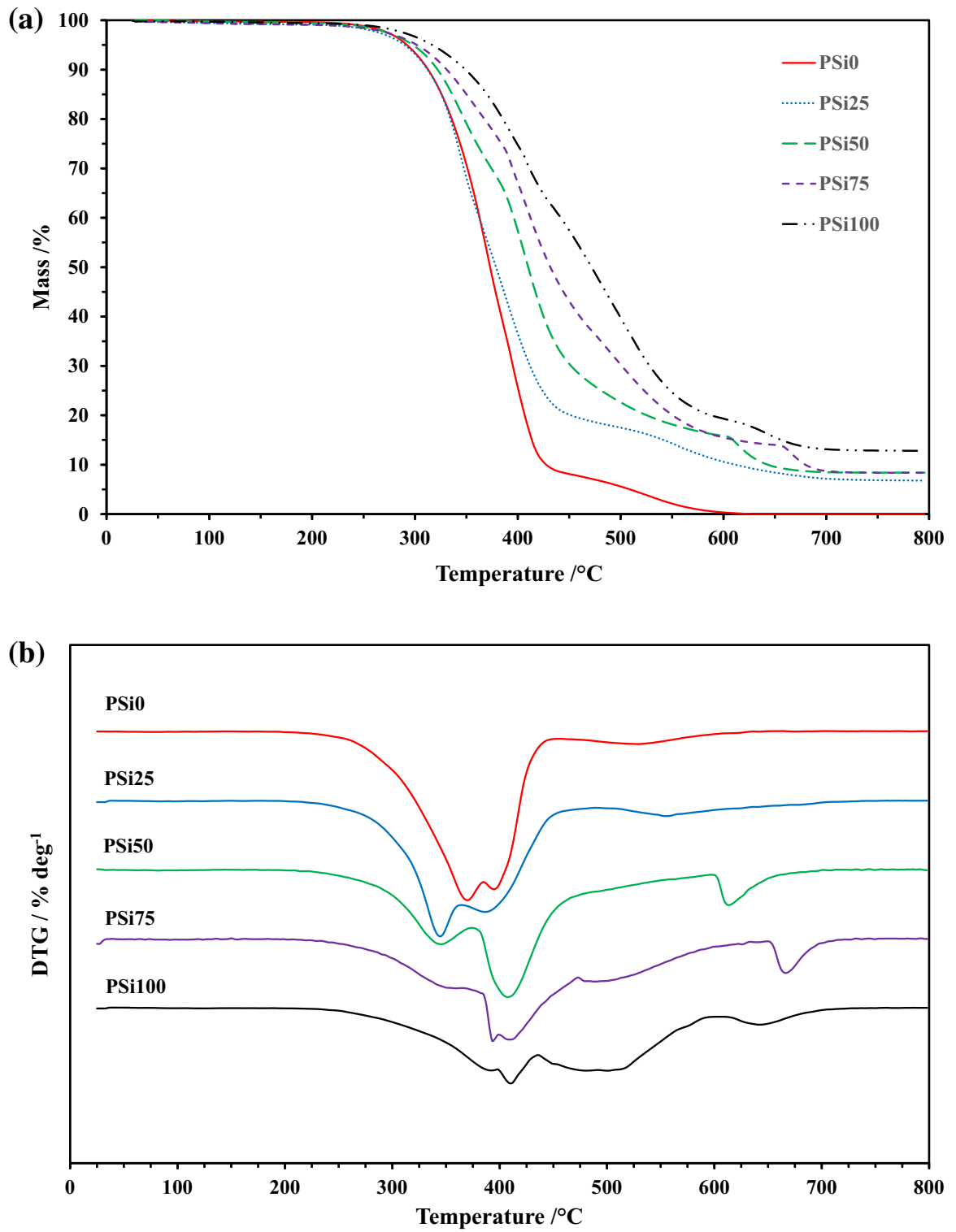

Fig. 6 TG (a) and DTG (b) curves of poly(urethane-siloxane) hybrid materials in air

evidenced on the DTG curve as a broad peak in the range of $450-680{ }^{\circ} \mathrm{C}$. The temperature of the maximum rate of weight loss at this step $\left(T_{\max 3}\right)$ is to $530{ }^{\circ} \mathrm{C}$. The first, second and third step of PSi0 decomposition is accompanied by drop in weight loss of $60.1,31.9$ and $8.0 \%$, respectively.

The most complex degradation mechanism among all the studied samples reveals PSi100 sample. The presence of at least four stages of degradation with the 
Table 3 Interpretation of TG and DTG curves of poly(urethane-siloxane) samples recorded at $10{ }^{\circ} \mathrm{C}$ $\min ^{-1}$ in air

\begin{tabular}{lllllllllll}
\hline Sample & $\begin{array}{l}T_{5} \% \\
\left({ }^{\circ} \mathrm{C}\right)\end{array}$ & $\begin{array}{l}T_{\max 1} \\
\left({ }^{\circ} \mathrm{C}\right)\end{array}$ & $\begin{array}{l}\Delta m_{1} \\
(\%)\end{array}$ & $\begin{array}{l}T_{\max 2} \\
\left({ }^{\circ} \mathrm{C}\right)\end{array}$ & $\begin{array}{l}\Delta m_{2} \\
(\%)\end{array}$ & $\begin{array}{l}T_{\max 3} \\
\left({ }^{\circ} \mathrm{C}\right)\end{array}$ & $\begin{array}{l}\Delta m_{3} \\
(\%)\end{array}$ & $\begin{array}{l}T_{\max 4} \\
\left({ }^{\circ} \mathrm{C}\right)\end{array}$ & $\begin{array}{l}\Delta m_{4} \\
(\%)\end{array}$ & $\begin{array}{l}\text { Remaining } \\
\text { mass }(\%)\end{array}$ \\
\hline PSi0 & 292 & 372 & 60.1 & 397 & 31.9 & 530 & 8.0 & - & - & 0 \\
PSi25 & 290 & 345 & 40.7 & 388 & 41.2 & 555 & 11.0 & - & - & 7.1 \\
PSi50 & 298 & 346 & 30.5 & 409 & 53.3 & - & - & 614 & 7.8 & 8.4 \\
PSi75 & 302 & 360 & 20.0 & $394^{\mathrm{a}}$ & $12.8^{\mathrm{a}}$ & 490 & 23.0 & 667 & 5.4 & 8.7 \\
& & & & $412^{\mathrm{a}}$ & $30.1^{\mathrm{a}}$ & & & & & \\
PSi100 & 317 & 393 & 24.7 & 411 & 13.8 & 501 & 49.3 & 642 & 5.7 & 13.0 \\
& & & & & & & & & &
\end{tabular}

\footnotetext{
a Split peak

b Shoulder peak
}

temperature of the maximum rate of weight loss of $393,411,501$ and $642{ }^{\circ} \mathrm{C}$, was noticed. However, for some of degradation steps the occurrence of shoulder and split peaks is observed, which hinders a clear analysis.

The poly(urethane-siloxane) thermosets decompose in air in at least three major steps. Thermooxidation takes place at a wider temperature range of $180-800{ }^{\circ} \mathrm{C}$ as compared to nitrogen. However, due to the presence of oxygen the degradation is more complex. The first stage of the degradation occurs at $180-370{ }^{\circ} \mathrm{C}$. However, this step is not present for PSi100 sample, which may suggest that the initial step of decomposition of the poly(urethane-siloxane) thermosets is associated with urethane bond scission. Additionally, for the copolymer sample with the highest siloxane content PSi75 as well as for PSi100 the occurrence of additional degradation step on DTG curve in the range of $470-650{ }^{\circ} \mathrm{C}$ is observed.

For all the samples the temperature of $5 \%$ weight loss recorded in the air is lower compared to the nitrogen. With the increase of siloxane amount in the PSi samples the $T_{5} \%$ increases and attains the largest value of $317{ }^{\circ} \mathrm{C}$ for PSi100 sample. Moreover, the difference between the values of $T_{5} \%$ recorded in nitrogen and air for each sample increases with increasing siloxane content. The positive effect of employed EPS on the thermal stability of the hybrid materials is confirmed by this fact. Moreover, the amount of solid residue after degradation is larger than in nitrogen and amounts to $0-13 \mathrm{wt} \%$. This is an evidence for the formation of complex silicon-based structures during the thermooxidation process. Those structures are formed on the surface of the sample and create the insulating layer, which slows down further decomposition of the polymer, as it was observed for poly(urethane-siloxane) copolymers.

As one can notice, there are some differences in thermal decomposition of the poly(urethane-siloxane) thermosets in non-oxidizing and oxidizing medium. In nitrogen two steps of thermal degradation can be found. The first step is related to urethane bond scission and formation of carbon dioxide [20]. The second step involves scission of PTMO as well as siloxane segments [19]. In this stage two mechanisms of siloxane decomposition are probable: a molecular mechanism with 
formation of cyclic oligomers and a radical one occurring through homolytic Si$\mathrm{CH}_{3}$ bonds scission [21]. In the presence of oxygen the mechanism of thermal decomposition is more complex and involves four stages. We can assume that the initial stage is related to polyurethane chain and the mechanism can be reduced to depolymerization process followed radical breakdown of the polyol chain in conjunction with simple radical formation [20]. The next steps are associated with the oxidation of methyl groups from siloxane and depolymerization of siloxane chain catalyzed by oxygen leading to formation of cyclic oligomers [21].

\section{Contact angle (CA) and free surface energy (FSE)}

The contact angles and the free surface energy components for the PSi coatings are provided in Table 4 . The values of standard deviations for CA did not exceed $2^{\circ}$. The lowest CA for every standard liquid were observed for the unmodified crosslinked polyurethane coating $\mathrm{PSi} 0$, amounting to $48^{\circ}, 67^{\circ}, 84^{\circ}$ for diiodomethane, formamide and water, respectively. The contact angles for every model liquid increase with the increase of EPS content up to $50 \mathrm{wt} \%$ and then remain almost constant, which can be attributed to the equilibrium of concentration of the siloxane at the surface of the coating. Moreover, the CA increase with the increasing polarity of the model liquids in order: diiodomethane $<$ formamide $<$ water.

Similar trend as for CA is observed for the free surface energy results. The PSi coatings are generally slightly polar materials with the FSE in the range 26-29 $\mathrm{mJ} \mathrm{m}^{-2}$. The values of free surface energy obtained by both OwensWendt's, as well as van Oss-Good's method, are comparable. The largest value of FSE $\left(35 \mathrm{~mJ} \mathrm{~m}^{-2}\right)$ reveals the crosslinked polyurethane sample PSi0. With the decrease of EPU2 in the sample composition the free surface energy decreases to $26 \mathrm{~mJ} \mathrm{~m}^{-2}$ (PSi75), which additionally confirms the hydrophobic character of siloxane. The lowest FSE of $17 \mathrm{~mJ} \mathrm{~m}^{-2}$ reveals crosslinked siloxane sample (PSi100). The free surface energy of the PSi is lower compared to similar materials but obtained from EPU based on PTMO with Mn = 1000 [16], which may be related with lower amount of polar urethane moieties in PSi samples. In total free surface energy value calculated with van Oss-Good method (Eq. 1) $\gamma_{S}^{\mathrm{LW}}$ compound mainly predominates, related to long-range interactions. In case of the OwensWendt method (Eq. 3) the contribution of $\gamma_{S}^{\mathrm{d}}$ compound related to dispersion interactions into total FSE is significant.

\section{Persoz hardness}

The Persoz hardness of the cured poly(urethane-siloxane) coatings on glass plates is presented in Table 5. All the obtained coatings are generally soft with the relative hardness in the range of $0.12-0.43$. However, the largest hardness of 0.43 reveals crosslinked siloxane sample PSi100. This phenomenon is related to the specific comb-like structure of the employed siloxane, where additionally short glycidoxypropyl segments are present. Both factors result in denser crosslinked structure in PSi100 sample than in other coatings, comprising long linear PTMO 2000 


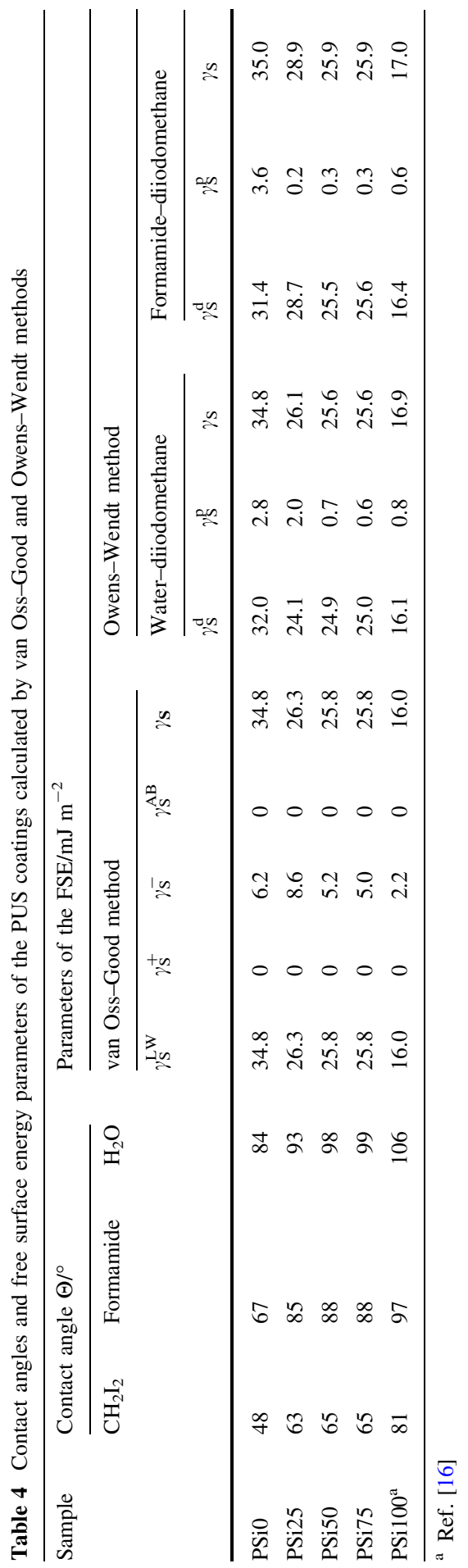


Table 5 The coating properties of the cured poly(urethanesiloxane)

${ }^{\mathrm{a}}$ Ref. [16]

\begin{tabular}{|c|c|c|c|c|}
\hline \multirow[t]{2}{*}{ Sample } & \multirow[t]{2}{*}{ Persoz hardness (-) } & \multicolumn{3}{|c|}{ Gloss [GU] } \\
\hline & & $20^{\circ}$ & $60^{\circ}$ & $85^{\circ}$ \\
\hline PSi0 & 0.12 & $33 \pm 7$ & $82 \pm 9$ & $58 \pm 6$ \\
\hline PSi25 & 0.14 & $33 \pm 9$ & $72 \pm 2$ & $82 \pm 2$ \\
\hline PSi50 & 0.16 & $31 \pm 3$ & $69 \pm 1$ & $90 \pm 2$ \\
\hline PSi75 & 0.24 & $25 \pm 1$ & $56 \pm 1$ & $77 \pm 5$ \\
\hline $\mathrm{PSi}_{100^{\mathrm{a}}}$ & 0.43 & $5 \pm 2$ & $19 \pm 4$ & $61 \pm 6$ \\
\hline
\end{tabular}

segments. The presence of urethane oligomer in the sample results in increasing the distance between siloxane chains as well as between network nodes. This makes the network less compact and more labile, which results in lowering of hardness. However, with the increase of siloxane in the sample increases also the contribution of crosslinker (Table 1) which forms network nodes and the system becomes more rigid. The Persoz hardness values for the obtained PUS coatings are generally larger compared to similar materials, but obtained from EPU based on PTMO with $M_{\mathrm{n}}=1000[16]$.

\section{Gloss}

The gloss of the cured poly(urethane-siloxane) coatings on glass plates at $20^{\circ}, 60^{\circ}$ and $85^{\circ}$ is presented in Table 5. The largest gloss at all the angles reveals PSi0 sample. With the introduction of siloxane the samples became less glossy. The coatings comprising siloxane reveal drop in gloss at $60^{\circ}$, especially for PSi75 sample. The PSi100 sample shows the lowest gloss among all the coatings. This may result from poor miscibility between siloxane segment and segment derived from DETA with polar $-\mathrm{OH}$ groups, which are formed during crosslinking. The gloss of PSi coatings at $60^{\circ}$ are generally higher in comparison to similar materials but obtained from EPU based on PTMO with lower molar mass, which may be related with better miscibility between siloxane and urethane segments in the former [16].

\section{Conclusions}

In this work a new approach to the method of synthesis of environmental friendly high-solids poly(urethane-siloxane) materials with the use of epoxy-functional compounds, is proposed. A series of novel crosslinked hybrid networks based on the epoxy-terminated urethane oligomer and the comb-like co-poly(dimethyl)(methyl, 3-glycidoxypropyl)siloxane cured with diethylenetriamine, were obtained. The structure of starting materials was confirmed by FTIR as well as ${ }^{1} \mathrm{H}$ and ${ }^{13} \mathrm{C}$ NMR spectroscopy. The structure of the obtained poly(urethane-siloxane) thermosets was confirmed by FTIR spectroscopy. The thermal stability of crosslinked polyurethane is improved by the addition of siloxane. With the increase of siloxane the 
temperature of $5 \%$ weight loss of the poly(urethane-siloxane) thermosets increases. Thermogravimetric studies carried out in nitrogen showed that the thermal degradation of poly(urethane-siloxane) thermosets is basically a two-stage process. The decomposition in air begins at lower temperature than in nitrogen and is more complex, involving at least three steps. The obtained poly(urethane-siloxane) networks are hydrophobic materials with the free surface energy of $26-29 \mathrm{~mJ} \mathrm{~m}^{-2}$. An increased amount of siloxane resulted in an increase of water contact angle as well as of FSE up to $50 \mathrm{wt} \%$ of siloxane and then remain constant, which confirms a hydrophobic nature of the employed siloxane. The coatings are generally soft with the relative hardness in the range of $0.14-0.24$. The incorporation of siloxanes resulted in gloss lowering.

Acknowledgments NMR spectra were recorded in the Laboratory of Spectrometry, Faculty of Chemistry, Rzeszow University of Technology and were financed from DS budget.

Open Access This article is distributed under the terms of the Creative Commons Attribution 4.0 International License (http://creativecommons.org/licenses/by/4.0/), which permits unrestricted use, distribution, and reproduction in any medium, provided you give appropriate credit to the original author(s) and the source, provide a link to the Creative Commons license, and indicate if changes were made.

\section{References}

1. Król P (2007) Synthesis methods, chemical structures and phase structures of linear polyurethanes. Properties and applications of linear polyurethanes in polyurethane elastomers, copolymers and ionomers. Prog Mater Sci 52:915-1015

2. Yilgör E, Yilgör I (2014) Silicone containing copolymers: synthesis, properties and applications. Prog Polym Sci 39:1165-1195

3. Rościszewski P, Zielecka M (2002) Silikony właściwości i zastosowanie. WNT, Warszawa

4. Rengasamy S, Mannari V (2013) Hydrophobic and oil-resistant coatings based on advanced green polyurethane dispersions. J Appl Polym Sci 130:3874-3884

5. Balaban M, Antić V, Pergal M, Godjevac D, Francolini I, Martinelli A, Rogan J, Djonlagić J (2013) Influence of the chemical structure of poly(urea-urethane-siloxane)s on their morphological, surface and thermal properties. Polym Bull 70:2493-2518

6. Pergal MV, Dzunuzovic JV, Poreba R, Micic D, Stefanov P, Pezo L, Spirkova M (2013) Surface and thermomechanical characterization of polyurethane networks based on poly(dimethylsiloxane) and hyperbranched polyester. Exp. Polym. Lett. 7:806-820

7. Naghash HJ, Mohammadidehcheshmeh I, Mehrnia M (2013) Synthesis and characterization of a novel hydroxy terminated polydimethylsiloxane and its application in the waterborne polysiloxaneurethane dispersion for potential marine coatings. Polym Adv Technol 24:307-317

8. Shi Z (2013) Preparation and characterization of crosslinked polyurethane-blockpoly(trifluoropropylmethyl)siloxane elastomers with potential biomedical applications. Polym. Intern. 62:1351-1357

9. Yilgor I, Eynur T, Bilgin S, Yilgor E, Wilkes GL (2011) Influence of soft segment molecular weight on the mechanical hysteresis and set behavior of silicone-urea copolymers with low hard segment contents. Polymer 52:266-274

10. Ekin A, Webster DC (2007) Combinatorial and high-throughput screening of the effect of siloxane composition on the surface properties of crosslinked siloxane-polyurethane coatings. J Comb Chem 9:178-188 
11. Byczyński Ł, Dutkiewicz M, Maciejewski H (2014) Thermal degradation studies of poly(urethanesiloxane) thermosets based on co-poly(dimethyl)(methyl, hydroxypolyoxyethylenepropyl)siloxane. Thermochim Acta 589:252-261

12. Byczyński $Ł ~(2013)$ Effect of different polyethers on surface and thermal properties of poly(urethane-siloxane) copolymers modified with side-chain siloxane. J Therm Anal Calorim 114:397-408

13. Sommer S, Ekin A, Webster DC, Stafslien SJ, Daniels J, Vander-Wal LJ, Thompson SEM, Callow ME, Callow JA (2010) A preliminary study on the properties and fouling-release performance of siloxane-polyurethane coatings prepared from poly (dimethylsiloxane)(PDMS) macromers. Biofouling 26:961-972

14. Edwards PA, Striemer G, Webster DC (2005) Novel polyurethane coating technology through glycidyl carbamate chemistry. JCT Res 2:517-528

15. Sun W, Yan X, Zhu X (2012) The synthetic kinetics and underwater acoustic absorption properties of novel epoxyurethanes and their blends with epoxy resin. Polym Bull 69:621-633

16. Byczyński Ł, Dutkiewicz M, Maciejewski H (2015) Synthesis and properties of high-solids hybrid materials obtained from epoxy functional urethanes and siloxanes. Prog Org Coat 84:59-69

17. van Oss CJ, Chaudhury MK, Good RJ (1988) Interfacial Lifshitz-van der Waals and polar interactions in macroscopic systems. Chem Rev 88:927-941

18. Owens DK, Wendt RC (1969) Estimation of the surface free energy of polymers. J Appl Polym Sci 13:1741-1747

19. Byczyński $€$ (2014) Thermal degradation studies of poly(urethane-siloxane) thermosets based on copoly(dimethyl)(methyl, 3-glycidoxypropyl)siloxane and epoxy-terminated urethane oligomer. Thermochim Acta 592:58-66

20. Chattopadhyay DK, Webster DC (2009) Thermal stability and flame retardancy of polyurethanes. Prog Polym Sci 34:1068-1133

21. Fang W, Zeng X, Lai X, Li H, Chen W, Zhang Y (2015) Thermal degradation mechanism of addition-cure liquid silicone rubber with urea-containing silane. Thermochim Acta 605:28-36 